Recepción: 09/ 07 / 2018

Aceptación: 13 / 09 / 2018

Publicación: 01 / 11 / 2018

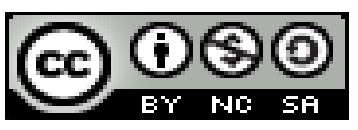

Ciencias económicas y empresariales

Artículo de investigación

\title{
Estudio del Régimen Impositivo simplificado RISE y su impacto en las recaudaciones globales
}

Study of the Simplified Tax Regime RISE and its impact on global collections
Estudo do Regime Tributário Simplificado RISE e seu impacto nas cobranças globais

\author{
Natalia Z. Largo-Sánchez ${ }^{\text {I }}$ \\ natylargo@gmail.com
}

Liliana J. Matailo-Yaguana II liliana3075@yahoo.es

\section{Correspondencia: natylargo@gmail.com}

\footnotetext{
${ }^{\mathrm{I}}$ Magister en Educación a Distancia, Magister en Auditoria Integral, Licenciada en Contabilidad y Auditoría, Contador Público-Auditor, Docente de la Universidad Nacional de Loja, Loja, Ecuador.
}

II Docente de la Universidad Nacional de Loja, Loja, Ecuador. 


\title{
Resumen
}

El estudio se efectúa para identificar la importancia del RISE en Ecuador, siendo un tributo directo y que fue creado con el fin de armonizar el flujo de entradas de divisas al estado para solventar el gasto social; su crecimiento es notable desde que entró en vigencia en el Registro Oficial debido a los beneficios que brinda a los sujetos pasivos en lo referente a créditos que pueden acceder si están inscritos en esta modalidad impuesta por el Servicio de Rentas Internas, como órgano rector de los impuestos en el país; en los resultados se destaca el aporte del tributo a las recaudaciones globales, así como el desglose de aportación de cada provincia que integra la zona de planificación 7 determinada por la SENPLADES, la metodología es de carácter mixto haciéndose imprescindible los enfoques cualí y cuantitativos para dar resultados objetivos que contribuyan a la realización de nuevas investigaciones que promuevan la eficiencia en el control de los tributos legalmente establecidos.

Palabras clave: RISE; tributo directo; entradas; sujeto pasivo.

\begin{abstract}
The study is carried out to identify the importance of the RISE in Ecuador, being a direct tribute and that was created in order to harmonize the flow of foreign currency inflows to the state to cover social spending; Its growth is notable since it entered into force in the Official Registry due to the benefits it provides to taxpayers in relation to credits that can be accessed if they are enrolled in this modality imposed by the Internal Revenue Service, as the governing body of the taxes in the country; in the results the contribution of the tribute to the global collections is highlighted, as well as the breakdown of contribution of each province that integrates the planning area 7 determined by the SENPLADES, the methodology is of a mixed nature becoming indispensable the qualitative and quantitative approaches to give objective results that contribute to the realization of new investigations that promote efficiency in the control of legally established taxes.
\end{abstract}

Key words: RISE; direct tribute; tickets; passive subject.

\section{Resumo}

O estudo foi feito para identificar a importância do aumento no Equador, sendo um imposto direto que foi criado a fim de harmonizar o fluxo de entrada de divisas para o estado para 
financiar despesas sociais; seu crescimento é notável desde que entrou em vigor no Diário Oficial por causa dos benefícios que ele proporciona aos contribuintes em termos de créditos que podem acessar se inscritos nesta modalidade imposta pela Receita Federal, como o corpo governante do impostos no país; resulta tributo de entrada para as receitas globais, bem como a repartição da contribuição de cada província que integra a área de planejamento 7 determinado pela SENPLADES está, a metodologia é de caráter misto tornando-se essencial para as abordagens qualitativas e quantitativas para dar resultados objetivos que contribuem para a realização de novas investigações que promovam a eficiência no controle dos impostos legalmente estabelecidos.

Palavras chave: RISE; tributo direto; bilhetes; sujeito passivo.

\section{Introducción}

La administración del sector público, en su afán de mejorar e incrementar su capacidad de recaudación de sectores que tradicionalmente no tributaban, ejecuta estrategias que les genere un mayor flujo de efectivo para desarrollar sus planificaciones anuales, y que, a su vez, les permita tener un control más eficiente de las fluctuaciones de la economía local, base fundamental para la creación de políticas que beneficien los sectores menos favorecidos. Una de las estrategias es la implementación del Régimen Impositivo Simplificado del Ecuador RISE, que permite que las microempresas puedan acogerse a este sistema, cancelando un valor fijo por concepto del impuesto al valor agregado IVA e impuesto a la renta IR, dependiendo del sector al que pertenece y a su capacidad de generar riqueza.

En la presente investigación, se realiza un estudio a la evolución de este tributo RISE, a través de los últimos años, y su impacto en las arcas fiscales, que es de donde se obtiene el financiamiento necesario para el suministro de servicios básicos y obras fundamentales que requieren todos los sectores productivos del país. Finalmente se emiten las respectivas conclusiones a las que llegan los autores, con el fin de contribuir a nuevas investigaciones que fortalezcan el mayor control de los tributos en el Ecuador. 


\section{Tributación}

La tributación es la actividad por la cual los contribuyentes o sujetos pasivos, deben cancelar al estado ciertos valores económicos por la prestación de un servicio gubernamental o por iniciar una actividad económica; el estado se nutre de estos ingresos directos para financiar su Presupuesto General y solventar el gasto social en educación, vivienda, salud, entre otros. En su análisis, Barros (2013) destaca que la tributación es la herramienta principal de la política fiscal de los gobiernos, con lo cual, se recauda liquidez que es destinada a la provisión de bienes y servicios públicos prioritarios.

Etimológicamente la palabra tributo, proviene del latín tributum, que significa, imposición, carga, gravamen, y aparece como tal en el año 162 antes de Cristo en Imperio romano que necesitaba de recursos financieros para financiar sus campañas militares con el fin de lograr el expansionismo que obtuvieron a través de siglos de conquista por toda Europa.

Según, Méndez (2003) que cita al autor Adam Smith, para comprender la tributación es importante establecer las siguientes premisas:

Los vasallos (contribuyentes) de cualquier estado legalmente establecido, están en la obligación de tributar para el sostenimiento del mismo (gobierno) en relación a sus respectivas facultades.

Todo tributo que es cancelado por los sujetos pasivos, debe ser cierto y determinado, en otro sentido, debe estar debidamente legalizado y aprobado por las administraciones tributarias, no puede ser arbitrario.

Para el cobro de los tributos, la administración encargada de efectuarlo, debe programar el tiempo y el modo de hacerlo, de tal forma que sea el más conveniente a las circunstancias del contribuyente.

Toda contribución, debe disponerse del modo, que de los contribuyentes se saque lo menos posible y sobre todo que en verdad entre a las arcas del estado para el cumplimiento de sus funciones.

Para, Moore(2007) es muy importante recordar y analizar de forma permanente, como se financian los gobiernos y como gobiernan, debido a que un país puede contar con un adecuado escenario en cuanto a la cultura tributaria y recaudación y por el contrario sus gobernantes no 
tengan la preparación necesaria para redistribuir la riqueza de manera equitativa y justa; o a su vez, se tenga el caso de que exista la voluntad y el conocimiento necesario para cambiar la situación de un país, pero no exista una cultura tributaria eficiente, o finalmente, no exista ni el conocimiento ni la cultura necesaria para desempeñar una gestión gubernamental adecuada.

En este sentido, es importante destacar que los contribuyentes desde su origen y composición, estuvieron contrarios a los tributos, por tal razón, y más, en los países subdesarrollados, la administración tributaria, tiene una fuerte oposición a las disposiciones en materia de recaudación, haciéndose necesario la publicidad de los beneficios que ello contrae, si se manejan de forma responsable y en conformidad con los dispuesto en las normativas legales para el efecto (Hernández 2011).

\section{Tributación en Ecuador}

En la normativa ecuatoriana, particularmente en el Código Tributario, se expresa lo siguiente con respecto a los tributos:

Art. 5.- Principios tributarios. - El régimen tributario se regirá por los principios de legalidad, generalidad, igualdad, proporcionalidad e irretroactividad.

Art. 6.- Fines de los tributos. - Los tributos, además de ser medios para recaudar ingresos públicos, servirán como instrumento de política económica general, estimulando la inversión, la reinversión, el ahorro y su destino hacia los fines productivos y de desarrollo nacional; atenderán a las exigencias de estabilidad y progreso sociales y procurarán una mejor distribución de la renta nacional.

\section{Los tributos en Ecuador se clasifican en:}

Impuestos: es el pago que efectúa el sujeto pasivo de la tributación, sin que el estado preste un servicio o contraprestación de un servicio al contribuyente, entre los más conocidos están el Impuesto al Valor Agregado IVA, Impuesto a la Renta, Impuesto a la Salida de Divisas.

Tasas: es el pago que efectúa el beneficiario de un servicio individualizado por parte del estado a través de las instituciones que lo conforman, entre los más destacados se tiene al alcantarillado, agua potable, cedulación, entre otros. 
Contribuciones especiales: es el pago que efectúa el contribuyente por una obra realizada por una entidad pública y que le beneficia de forma directa, aquí es individual sino colectivo el beneficio que tienen por la realización de la obra, ejemplo arreglo de parques, vías, entre otros.

\section{Impuestos}

Los impuestos han estado desde épocas antiquísimas en relación directa con la forma de gobernar del ser humano, son indispensables para lograr metas futuras, que se trazan las administraciones en concordancia de las necesidades básicas de la población. Hoy en día se puede afirmar que existe una mejor gestión en el manejo y control de los impuestos, recordando que para el año de 1830 los impuestos directos eran considerados, los aplicados al tributo de indios y el diezmo (Paz \& Miño, 2015).

En su análisis, Tortolero (2014) exponen el concepto que más se ajusta a los impuestos y es:

Es una prestación de dinero que de manera coactiva es exigida al sujeto pasivo por el titular de la potestad tributaria, cuando ocurre el presupuesto previsto en la ley como hecho imponible, y cuyo pago no está vinculado en modo alguno a la obtención de algún servicio u otra actividad prestacional por parte del ente respectivo (p.150).

Con ello se puede afirmar que los impuestos son un parte muy importante dentro de las políticas públicas y económicas de un país, contribuyendo a la entrada de divisas que son destinadas a mejorar la calidad de vida de todos los contribuyentes; estos impuestos puede derivarse de varias actividades o por sectores, y es el Servicio de Rentas Internas SRI para el caso de Ecuador, el encargado de velar por el correcto manejo y uso de los recursos, cuyo fin principal es el gasto o inversión social.

Los impuestos se clasifican en directos e indirectos, la principal característica que los distingue en que los primeros se encargan de gravar las rentas o ingresos de los contribuyentes, mientras que los segundos se direccionan en cualquier otro sentido menos a las utilidades obtenidas por los sujetos pasivos de la tributación.

\section{Presupuesto General del Estado PGE}

En el portal del Ministerio de Economía y Finanzas del Ecuador se puede encontrar la definición de PGE, en su parte pertinente señala que: es la estimación de los ingresos que se espera percibir durante un periodo económico y en que se invertirá dichos recursos, es una herramienta 
fundamental que permite armonizar todas las actividades de todas las instituciones del estado. En su análisis, Iregui (2006) señalan que el PGE es uno de los principales instrumentos de la política económica y que refleja las decisiones que se deben tomar sobre impuestos a aplicar, deuda y gasto social prioritario.

Para, Pérez (2015) una de las metodologías que más se ajusta en la elaboración del presupuesto del estado, es el denominado Presupuesto Bajo Cero PBC, que tuvo sus orígenes en el sector privado, en las grandes corporaciones de Estados Unidos y elaborado por Peter Phyrr como medida para solventar dificultades futuras; el PBC consiste en reevaluar cada uno de los programas y gastos, siempre partiendo desde cero, evaluando y justificando los montos de cada inversión, con el fin de lograr mayor armonía y control en los recursos del estado que tienen un fin social común.

De manera general, Paz \& Miño (2015) presentan en su obra, el esquema del presupuesto general del estado, quedando de la siguiente forma:

Tabla 1. Resumen de un presupuesto gubernamental

\begin{tabular}{|c|c|c|c|}
\hline \multicolumn{2}{|c|}{ INGRESOS } & \multicolumn{2}{|c|}{ GASTOS } \\
\hline Ingresos corrientes & $\begin{array}{l}\text { 1. Impuestos } \\
\text { Tributarios } \\
\text { - Impuestos } \\
\text { directos } \\
\text { - Impuestos } \\
\text { indirectos } \\
\text { 2. Impuestos } \\
\text { no tributarios } \\
\text { - Servicios públicos } \\
\text { - Rentas sobre } \\
\text { bienes y recursos } \\
\text { del estado } \\
\text { - Empresas } \\
\text { estatales }\end{array}$ & \multirow[t]{2}{*}{$\begin{array}{l}\text { Gastos } \\
\text { corrientes }\end{array}$} & \multirow{2}{*}{$\begin{array}{l}\text { 1. Gastos de } \\
\text { consumo } \\
\text { - Remuneraciones } \\
\text { - Compra de bienes y } \\
\text { servicios de } \\
\text { consumo } \\
\text { 2. Gastos de } \\
\text { transferencia } \\
\text { - Intereses de la deuda } \\
\text { publica } \\
\text { - Aportes al sector } \\
\text { privado lucrativo } \\
\text { - Aportes a entidades } \\
\text { no lucrativas } \\
\text { 3. Gastos de } \\
\text { capital } \\
\text { - Inversión real: } \\
\text { bienes y servicios } \\
\text { provistos por el } \\
\text { estado } \\
\text { - Inversión financiera } \\
\text { - Amortizaciones } \\
\text { - otros }\end{array}$} \\
\hline $\begin{array}{l}\text { Ingresos } \\
\text { extraordinarios }\end{array}$ & $\begin{array}{l}\text { - Endeudamiento } \\
\text { interno } \\
\text { - Endeudamiento } \\
\text { externo } \\
\text { - Variación de } \\
\text { saldos de caja } \\
\text { - Otros }\end{array}$ & & \\
\hline
\end{tabular}

Fuente: Paz y Miño 2015 
Del estudio realizado por, Castañeda \& Villagómez, (2008) se destaca que la dependencia de los gastos públicos de un estado sobre los ingresos petroleros es considerada como negativa, por cuanto el recurso natural es volátil, no renovable y que su precio en el mercado es altamente cambiante y puede afectar las planificaciones o presupuestos que se efectúan sobre un valor base. De ahí que se debe buscar las alternativas necesarias para financiar los presupuestos con recaudaciones que son más fáciles de controlar por la administración gubernamental, disminuyendo el riesgo por factores externos que limiten su capacidad de acción.

\section{Régimen Impositivo Simplificado del Ecuador RISE}

El RISE es un nuevo régimen de incorporación voluntaria, reemplaza el pago del IVA y del Impuesto a la Renta a través de cuotas mensuales y tiene por objeto mejorar la cultura tributaria en el país.

\section{¿Cuándo y dónde se puede incorporar al RISE?}

Se pueden incorporar al Régimen Simplificado a partir del 1 de agosto de 2008. Para inscribirse pueden hacerlo en cualquier oficina del SRI a nivel nacional o a través de brigadas móviles, adicionalmente se dispone del servicio de preinscripción vía Internet, luego deberá acercarse a una ventanilla exclusiva para culminar el proceso de inscripción al RISE, de esta manera disminuirá el tiempo de espera. Recuerde: las cuotas RISE empiezan a ser pagadas desde el mes siguiente al de la inscripción

\section{¿Cuáles son las condiciones y requisitos que debe cumplir una persona que quiera acogerse al RISE?}

Ser persona natural

No tener ingresos mayores a USD 60,000 en el año, o si se encuentra bajo relación de dependencia el ingreso por este concepto no supere la fracción básica del Impuesto a la Renta gravada con tarifa cero por ciento $(0 \%)$ para cada año

No dedicarse a alguna de las actividades restringidas

No haber sido agente de retención durante los últimos 3 años. 


\section{¿Qué beneficios ofrece el RISE?}

No necesita hacer declaraciones, por lo tanto, se evita los costos por compra de formularios y por la contratación de terceras personas, como tramitadores, para el llenado de los mismos

Se evita que le hagan retenciones de impuestos

Entregar comprobantes de venta simplificados en los cuales solo se llenará fecha y monto de venta

No tendrá obligación de llevar contabilidad

Por cada nuevo trabajador que incorpore a su nómina y que sea afiliado en el IESS, Ud. podrá solicitar un descuento del 5\% de su cuota, hasta llegar a un máximo del 50\% de descuento.

\section{¿Qué tipo de actividades no pueden inscribirse en el RISE?}

Existen ciertas actividades económicas que NO pueden incorporarse al Régimen Simplificado.

Actividades excluidas del Régimen Impositivo Simplificado Ecuatoriano RISE

\section{Actividades económicas que no pueden acogerse al RISE:}

De agenciamiento de Bolsa;

De propaganda y publicidad;

De almacenamiento o depósito de productos de terceros;

De organización de espectáculos públicos;

Del libre ejercicio profesional que requiera título terminal universitario;

De agentes de aduana;

De producción de bienes o prestación de servicios gravados con el Impuesto a los Consumos Especiales;

De personas naturales que obtengan ingresos en relación de dependencia, salvo lo dispuesto en esta Ley;

De comercialización y distribución de combustibles; 
De impresión de comprobantes de venta, retención y documentos complementarios realizadas por establecimientos gráficos autorizados por el SRI;

De casinos, bingos y salas de juego;

De corretaje de bienes raíces;

De comisionistas;

De arriendo de bienes inmuebles;

De alquiler de bienes muebles;

De naturaleza agropecuaria, contempladas en el artículo 27 contempladas en la Ley de Régimen Tributario Interno;

Extracción y/o comercialización de sustancias minerales metálicas.

\section{¿Si me inscribo en el RISE que tipo de comprobante de venta debo entregar?}

Un contribuyente RISE entregará comprobantes de venta simplificados, es decir notas de venta o tiquete de máquina registradora autorizada por el SRI, para los requisitos de llenado solo deberá registrarse la fecha de la transacción y el monto total de la venta (no se desglosará el 12\% del IVA).

Los documentos emitidos sustentarán costos y gastos siempre que identifiquen al consumidor y se detalle el bien y/o servicio transferido. Un contribuyente inscrito en el RISE tiene la obligación de emitir y entregar comprobantes de venta por transacciones superiores a US\$12,00, sin embargo, a petición del comprador, estará en la obligación de entregar el comprobante por cualquier valor.

Al final de las operaciones de cada día, se deberá emitir una nota de venta resumen por las transacciones realizadas por montos inferiores o iguales a US\$12,00 por lo que no se emitió un comprobante.

\section{Importancia del Problema}

Es importante el estudio del régimen impositivo simplificado como aporta al presupuesto del estado a través de las rentas fiscales, además contribuye a la determinación de estrategias para 
evitar la evasión de impuestos por parte de los pequeños negocios que se encuentran inmersos en el sistema y fomentar la cultura tributaria.

\section{Metodología}

La investigación es de carácter cualitativo y cuantitativo, la primera por cuanto se delimitan los conceptos más relacionados al tema de investigación con el fin de dar u soporte teórico de los cálculos efectuados en la parte práctica, que en sí, viene a constituir el enfoque cuantitativo del estudio, por la utilización de las matemáticas y estadísticas para representar los respectivos resultados.

Se utilizó el método deductivo para generalizar el marco referencial de la literatura y resumir lo más destacado de la misma, de la misma forma se hizo necesario el método inductivo para ir analizando varios parámetros con respecto al RISE y su evolución en el Ecuador, para llegar a conclusiones generales que sirvan de conocimiento para los usuarios y como punto de partida para nuevas investigaciones.

\section{Resultados}

Tabla 2. Recaudación del RISE en relación a la recaudación global de todos los impuestos.

\begin{tabular}{|c|r|r|r|}
\hline $\begin{array}{c}\text { AÑOS } \\
\text { RECAUDACIÓN }\end{array}$ & $\begin{array}{c}\text { RECAUDACIÓ } \\
\text { N GLOBAL }\end{array}$ & $\begin{array}{c}\text { RECAUDACIÓN } \\
\text { RISE }\end{array}$ & $\begin{array}{c}\text { PORCENTAJE } \\
\text { APORTACION } \\
\text { RISE }\end{array}$ \\
\hline 2010 & 7.864 .667 .902 & 5.744 .895 & 0,07305 \\
\hline 2011 & 8.721 .173 .296 & 9.524 .212 & 0,10921 \\
\hline 2012 & 11.090 .656 .509 & 12.217 .796 & 0,11016 \\
\hline 2013 & 12.757 .722 .174 & 15.197 .422 & 0,11912 \\
\hline 2014 & 13.616 .817 .193 & 19.564 .371 & 0,14368 \\
\hline 2015 & 13.950 .016 .013 & 20.015 .866 & 0,14348 \\
\hline 2016 & 12.226 .780 .510 & 18.783 .202 & 0,15362 \\
\hline
\end{tabular}

Fuente: Servicio de Rentas Internas 2017

En la recaudación global se consideran tanto los impuestos directos como los indirectos, es decir todos los ingresos por concepto de tributos, multas e intereses, en la tabla 1 se muestra la recaudación de todos los impuestos y los del sistema de Régimen Impositivo Simplificado a nivel 
nacional, es decir de las 24 provincias que conforman el Ecuador; para relacionar el aporte que representa el RISE en la recaudación de los ingresos globales observando que genera una participación mínima puesto que no supera el 0,20 por ciento, debido a que quienes están incluidos en este régimen son las personas que no sobrepasan los $\$ 60.000$ de ingresos anuales.

Tabla 3. Recaudación del RISE en relación a la recaudación de los impuestos directos.

\begin{tabular}{|c|r|r|r|}
\hline $\begin{array}{c}\text { AÑOS } \\
\text { RECAUDACIÓN }\end{array}$ & $\begin{array}{c}\text { IMPUESTOS } \\
\text { DIRECTOS }\end{array}$ & $\begin{array}{c}\text { RECAUDACIÓN } \\
\text { RISE }\end{array}$ & $\begin{array}{c}\text { PORCENTAJE } \\
\text { APORTACION } \\
\text { RISE }\end{array}$ \\
\hline 2010 & 3.572 .008 .066 & 5.744 .895 & 0,16083 \\
\hline 2011 & 3.873 .450 .519 & 9.524 .212 & 0,24588 \\
\hline 2012 & 5.066 .283 .539 & 12.217 .796 & 0,24116 \\
\hline 2013 & 5.811 .421 .626 & 15.197 .422 & 0,26151 \\
\hline 2014 & 6.266 .004 .334 & 19.564 .371 & 0,31223 \\
\hline 2015 & 6.538 .325 .758 & 20.015 .866 & 0,30613 \\
\hline 2016 & 10.773 .419 .241 & 18.783 .202 & 0,17435 \\
\hline
\end{tabular}

Fuente: Servicio de Rentas Internas 2017

Los impuestos directos están conformados por Impuesto a la Renta, Impuesto a los Vehículos Motorizados, Impuesto a la Salida de Divisas, Impuesto a los Activos en el exterior, Régimen Impositivo Simplificado, Regalías, patentes y utilidades de conservación minera, Tierras Rurales, Intereses por mora tributaria, y Multas tributarias fiscales, en la tabla se hace relación a la participación que tiene el Régimen Impositivo Simplificado en relación al grupo de impuestos directos expresando en un porcentaje mínimo de $0.30 \%$; los años en que mayor participación ha tenido han sido en el 2014 con 0,31223\% y 2015 con $0.30613 \%$; en el año 2016 se evidencia una disminución debido al terremoto que afecto parte de la costa ecuatoriana. 
Tabla 3. Representa la recaudación por concepto del impuesto Régimen Impositivo Simplificado RISE

\begin{tabular}{|c|r|r|r|c|}
\hline \multicolumn{1}{|l|}{ AÑO } & \multicolumn{1}{|c|}{ ZONA 7 } & TOTAL PAIS & $\begin{array}{c}\text { \% } \\
\text { RECAUDADO } \\
\text { ZONA 7 }\end{array}$ & $\begin{array}{c}\text { DIFERENCIA } \\
\text { PORCENTUAL }\end{array}$ \\
\hline 2010 & $884.945,34$ & $5.744 .895,00$ & 15,40 & \\
\hline 2011 & $1.321 .316,26$ & $9.524 .212,00$ & 13,87 & $-1.53 \%$ \\
\hline 2012 & $1.473 .183,88$ & $12.217 .796,00$ & 12,06 & $-1.83 \%$ \\
\hline 2013 & $1.731 .380,15$ & $15.197 .422,00$ & 11,39 & $-0.67 \%$ \\
\hline 2014 & $2.136 .548,15$ & $19.564 .400,00$ & 10,92 & $-0.47 \%$ \\
\hline 2015 & $2.145 .283,10$ & $20.016 .000,00$ & 10,72 & $-1.20 \%$ \\
\hline 2016 & $2.161 .003,25$ & $18.783 .000,00$ & 11,51 & $0.79 \%$ \\
\hline
\end{tabular}

Fuente: Servicio de Rentas Internas 2017

Gráfico 1. Relación recaudación global con Zona 7

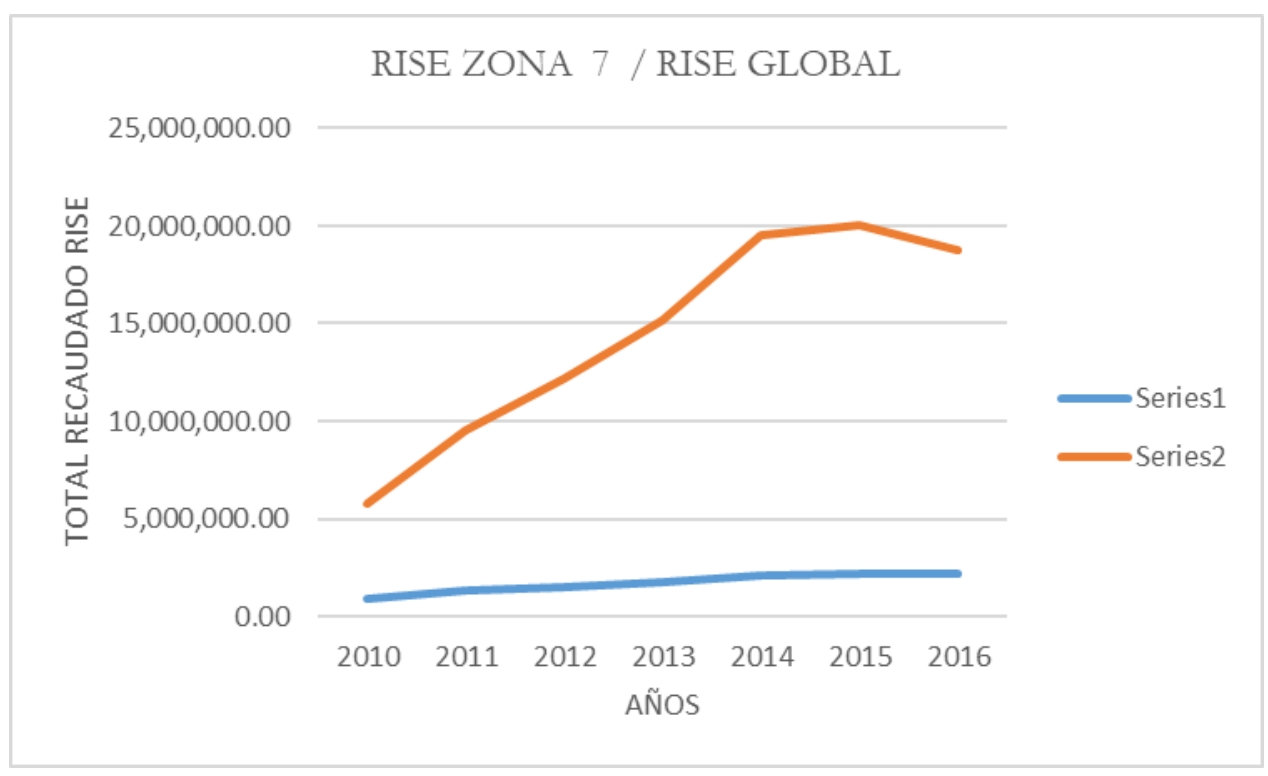

Se realizó un análisis comparativo de la recaudación en la Zona 7 del RISE en relación a lo que representan los ingresos globales por concepto de este impuesto. Observando la tabla 1 sobre los valores recaudados desde el año 2010 los montos de recaudación en la zona 7 han ido incrementando mientras que si observamos los porcentajes en relación a las rentas globales del mismo impuesto, en el año 2010 alcanza 15.40\% mientras que en los otros años la recaudación de zona disminuye presentándose porcentajes variables, así en el año 2011 decrece en 1.53\%, en el 
2012 en $1.83 \%$ puntos porcentuales ; en el 2013 en $0,67 \%$; en el 2014 en $0,47 \%$ en el 2015 prácticamente se mantiene fija en relación al año anterior, en el 2016 se visualiza en leve crecimiento en $0.79 \%$.

Tabla 4. Recaudación RISE de la Zona 7 por provincias.

\begin{tabular}{|l|c|c|c|c|c|c|c|}
\hline \multicolumn{1}{|c|}{ ZONA 7 } & 2010 & 2011 & 2012 & 2013 & 2014 & 2015 & 2016 \\
\hline EL ORO & $622.094,71$ & $891.493,70$ & $930.588,29$ & $1.100 .664,79$ & $1.392 .673,38$ & $1.446 .984,48$ & $1.501 .163,58$ \\
\hline LOJA & $196.543,90$ & $318.329,87$ & $393.890,45$ & $455.044,27$ & $552.365,04$ & $539.755,41$ & $513.600,42$ \\
\hline $\begin{array}{l}\text { ZAMORA } \\
\text { CHINCHIPE }\end{array}$ & $66.306,73$ & $111.492,69$ & $148.705,14$ & $175.671,09$ & $191.509,73$ & $158.543,21$ & $146.239,25$ \\
\hline Total general & $\mathbf{8 8 4 . 9 4 5 , 3 4}$ & $\mathbf{1 . 3 2 1 . 3 1 6 , 2 6}$ & $\mathbf{1 . 4 7 3 . 1 8 3 , 8 8}$ & $\mathbf{1 . 7 3 1 . 3 8 0 , \mathbf { 1 5 }}$ & $\mathbf{2 . 1 3 6 . 5 4 8 , \mathbf { 1 5 }}$ & $\mathbf{2 . 1 4 5 . 2 8 3 , \mathbf { 1 0 }}$ & $\mathbf{2 . 1 6 1 . 0 0 3 , 2 5}$ \\
\hline
\end{tabular}

Fuente: Servicio de Rentas Internas 2017

La tabla 2 representa la recaudación del impuesto de la Zona 7, es decir las provincias de El Oro, Loja y Zamora Chinchipe; observándose un incremento gradual en los años de estudio, siendo la provincia de El Oro la que más ha recaudado desde el año 2010 hasta el año 2016, esto por el número de habitantes y por el sinnúmero de pequeños negocios de personas naturales, que se han incorporado al sistema de régimen simplificado, en el último año 2016 asciende la provincia de El Oro al 5,48\%; siguiendo la provincia de Loja con la incorporación del 3,01\% y por último la provincia con menos población de Zamora Chinchipe con el 0,91\% en relación a la incorporación global al sistema.

\section{Conclusiones}

De la investigación realizada se puede concluir que el Régimen Impositivo Simplificada aporte al presupuesto nacional un porcentaje mínimo.

La política del gobierno nacional para insertar a las personas naturales no obligadas a llevar contabilidad con ingresos anuales hasta $\$ 60.000,00$ no representan un valor significativo para el presupuesto general sin embargo fomenta la cultura tributaria y facilita el cumplimiento de las obligaciones con el Servicio de Rentas Internas.

En relación al aporte del Régimen Impositivo Simplificado de la Zona 7 ha la recaudación global de este impuesto fluctúa entre el 10\% y 15\%, manteniéndose en la zona un incremento gradual. 
Las provincias que conforman la Zona 7 son El oro, Loja y Zamora Chinchipe, siendo El Oro, la provincia que más contribuye en la recaudación de dicho impuesto.

\section{Referencias Bibliográficas}

Barros Vio, B. (2013). ¿POR QUÉ LAS PERSONAS PAGAN SUS IMPUESTOS? Subjetividad y Procesos Cognitivos, 38. Obtenido de www.redalyc.org/articulo.oa?id=339630262002

Castañeda, A., \& Villagómez, F. A. (2008). Ingresos fiscales petroleros y provisión óptima de bienes públicos. Investigación Económica, 16. Obtenido de www.redalyc.org/articulo.oa?id=60126501

Hernández Rodríguez, I. (2011). Tributación y desarrollo en perspectiva. Revista de Economía Institucional, 295. Obtenido de http://www.redalyc.org/articulo.oa?id=41921223009

Iregui B., A. M., Melo B., L., \& Ramos F., J. (2006). ¿Hacia dónde se dirigen los recursos de Inversión del Presupuesto General de la Nación? Revista Apuntes del CENES, 113. Obtenido de http://www.redalyc.org/articulo.oa?id=479548749007

Méndez Peña, M. (2003). Dimensiones Morales de los impuestos. Fermentum. Revista Venezolana de Sociología y Antropología, 337. Obtenido de http://www.redalyc.org/articulo.oa?id=70503707

Moore, M. (2007). ¿CÓMO AFECTA LA TRIBUTACIÓN A LA CALIDAD DE LA GOBERNACIÓN? El Trimestre Económico, 284. Obtenido de http://www.redalyc.org/articulo.oa?id=31340950006

Paz, J., \& Miño, C. (2015). Historia de los impuestos en Ecuador. Quito: Historia de los impuestos en Ecuador.

Pérez Partida, H. R. (2015). Reflexiones sobre el Presupuesto Base Cero y el Presupuesto basado en Resultados. El Cotidiano, 80. Obtenido de http://www.redalyc.org/articulo.oa?id=32539883010

Tortolero, B., \& Gamarra, F. (2014). Armonización del impuesto municipal: actividades económicas. Orbis. Revista Científica Ciencias Humanas, 150. Obtenido de http://www.redalyc.org/articulo.oa?id=70930407008 